\title{
PRIMERA NOTICIA DE LOS TRABAJOS ARQUEOLÓGICOS REALIZADOS EN EL YACIMIENTO ISLÁMICO DE LAS DUNAS DE GUARDAMAR DEL SEGURA (ALICANTE): UNA POSIBLE RÁBITA DE ÉPOCA CALIFAL
}

Por

RAFAEL AZUAR RUIZ

El pasado mes de diciembre se comenzaron, en un paraje denominado "El Pueblo Antiguon de las Dunas de Guardamar, unos trabajos de prospección arqueológica, bajo mi dirección y con la ayuda de los arqueólogos Manuel Gea, Antonio García y Nieves Roselló

Para la consecución de estos primeros trabajos ha sido inestimable la ayuda del Ayuntamiento de Guardamar, que ha puesto un gran interés, así como los medios necesarios que estuvieron a su alcance; igualmente ICONA, que puso a nuestra disposición una cuadrilla de diez hombres y la remuneración de uno de los arqueólogos, y por último la Diputación Provincial, que dispuso lo necesario para que el Museo, a través de mi persona y del equipo que lo forma, se hiciera cargo del control arqueológico de los trabajos.

El que se llegara a la realización de una prospección arqueológica en este paraje es fruto de una serie de motivos: a fines del siglo XIX se comenzaron los trabajos de consolidación de las Dunas de Guardamar; en estas labores, al hacer un surco para plantación de árboles, aparecieron una serie de muros, encontrándose en uno de ellos, incrustada, una lápida con signos árabes. A este lugar, el ingeniero Mira, encargado de estos trabajos, denominó en sus planos y notas personales como "Pueblo Antiguo". La lápida fue levantada, y posteriormente depositada, por unos familiares del insigne ingeniero; en el Museo de Bellas Artes de Murcia.

Pocos años después, el eminente arabista $F$. Codera estudiaba la lápida y publicaba su traducción (1897):

En el nombre de Alá, el Clemente, el Misericordioso. No (hav) Dios, sino Alá; Mahoma es el enviado de Alá; se concluyó esta mezquita en el mes de Almoharrem en el año tres y treinta y tres cientos: mandó construirla Ahmed, hijo de Bohlul, hijo de la hija de Alwatsecbilá, el que busca la re- 
compensa de Alá: (lo hizo) con auxilio (bajo la dirección a costa) de Mohammad, hijo de Abusalema: zobra de Aben Morracha? ... el constructor.

Codera, ante el carácter extraordinario de encontrarse con la lápida fundacional de una mezquita levantada en el año 944, planteó, en su trabajo, la necesidad de que se realizasen excavaciones en el lugar, pues como más tarde indicó Leví Provençal, era una de las pocas mezquitas rurales de época califal de las que se disponía su dato de identidad, así como la posibilidad de encontrarla.

En segundo lugar, tenemos que referimos al problema toponimico, ya que las fuentes, ya sean islámicas o cristianas, mencionan a este lugar, en la desembocadura del Segura, como "Almodóvar" las primeras, v "Guardamar" las segundas, es decir, no presentan una unidad de criterios para nominar al lugar, y esta cuestión sólo puede deberse a dos razones, una, que no se refieran al mismo lugar geográfico, y dos, que si es el mismo, responda a un posible desplazamiento de la población de un lugar a otro y por tal nos encontraríamos con un poblamiento de época islámica al que denominan las fuentes como "Almodóvar" ubicado en un lugar geográfico distinto al actual emplazamiento de Guardamar.

Por último, el hecho de que en el lugar de las dunas denominado «El Pueblo Antiguon, existieran unos restos visibles de obra de mampostería recogida con cal, de la que desconocíamos su existencia en épocas recientes, es decir, siglos XVI-XIX, nos hizo albergar la posibilidad de que estos restos fueran vestigios del posible edificio que proporcionó la lápida, a la vez que correspondiesen a ese antiguo "Almodóvar" de las fuentes islámicas.

\section{Excavación}

Con estos planteamientos comenzamos los trabajos el día 4 de diciembre de 1984, durando éstos cinco semanas. Abrimos una superficie de unos cuatrocientos metros cuadrados, distribuidos en cuatro sectores de cien metros cuadrados cada uno, emplazados en la zona en que afloraban los restos anteriormente mencionados.

La excavación de estos cuatro sectores nos ha permitido sacar a la luz un edificio de planta rectangular, de unos treinta y cinco metros de frente por cinco metros y medio en su parte más ancha, dividido en cuatro salas adosadas, que de Oeste a Este, poseen las siguientes medidas, exceptuando la primera, que está sin excavar: $8,60 \times 2,60$ metros, $10 \times 2,60$ metros, y 7,80 $\times 2,60$ metros; las medidas de anchura se han tomado en las partes centrales, pues como se observa en el plano, en los extremos presentan estos habitáculos unos desplazamientos de su muro de mediodía, que en conjunto dan la apariencia de constituir una planta ligeramente curva (plano I).

La orientación del edificio en su fachada mayor es a mediodía y tres de los habitáculos poseen su ingreso en esta fachada, mientras el otro, el de poniente, posee el ingreso en la fachada norte.

Los habitáculos poseen cada uno un "mihrab» a la altura de la mitad del muro de mediodía, y éstos presentan una estructura similar: son externos al edificio, de planta ligeramente rectangular al exterior $(2 \times 1,50$ metros, con zapata de 0,25 metros) y al interior de planta de herradura, siendo su alzado un 
arco de herradura y su sección una semibóveda de herradura. La obra es de mampostería recogida con cal al exterior y su fachada externa es de siliería, sin mantener un orden establecido, potenciándose el encadenado en las esquinas. La fachada interna era de sillería, del grosor del muro, pero sólo nos ha quedado la parte inferior, es decir, hasta la altura de la línea de imposta, pero por las características del terminado interior del muro, suponemos que esta fachada interna del "mihrab" presentaría un alfiz de silleria, y que definiría perfectamente, por su carácter monumental, el umihrab» del resto del edificio.

Las dimensiones de los arcos del "mihrab" de los habitáculos 2,3 y 4 , según el orden mencionado anteriormente, son idénticas y resultan ser las siguientes:

Altura: 2,25 metros.

Luz: 0,80 metros.

Altura línea de imposta: 1,30 metros.

Radio: 0,47 metros.

Elevado $1 / 3$ sobre la línea de imposta.

El "mihrab" del habitáculo primero presenta unas características distintas a los demás; asi, aunque es de sillería, ésta aparece totalmente enlucida y por lo tanto encubierta, no apreciándose a simple vista; por otro lado, el alfiz estaba pintado en rojo, como se aprecia en los restos que han quedado en su parte inferior a la altura de la línea de imposta, y por último, tiene una luz menor que los anteriores sólo de 0,50 metros, aunque la línea de imposta esté a la misma altura que las anteriores; por no conservarse la parte superior del umihrab" desconocemos las medidas que éste tenía.

Por las medidas expuestas, vemos que la unidad utilizada es el codo ma'muni, 0,47 centímetros (Vallvé, 1976), como se constata en los radios de los "mihrab" mencionados.

La factura del resto de los edificios corresponde a una mamposteria en "Opus spicatum", en hiladas de 0,25 metros de ancho y con un grosor de muro de un codo, aunque con ciertas irregularidades. La obra se recoge al exterior con cal, presentando en zonas un perfecto enlucido, en el que se aprecian las marcas de la «llana» o paleta de enlucidor. Los muros de los habitáculos que existen frente a este conjunto, presentan una misma técnica de aparejo, pero éste se realiza por medio de mortero y sin enlucir.

La altura de los muros sobrepasa en su mayoría el metro de vuelo, encontrándonos en el muro de mediodía alturas cercanas a los dos metros que nos hablan del estado perfecto en que se encuentra el edificio.

Los vanos o ingresos a los habitáculos de las mezquitas son de mampostería, con una luz que va de 0,70 a 0,80 metros; sin embargo, en los habitáculos advacentes las puertas presentan jambas de sillería colocadas en posición vertical.

Las entradas a las mezquitas se encuentran enlosadas $y$ en la tercera o principal hemos podido detectar la existencia de un quicio para la puerta y un hueco, más atrasado, para el cierre o pestillo. Estas entradas, asimismo, poseen en su parte exterior un enlosado de piedras, de más altura que el de la 
puerta, quizás con la función de evitar la entrada de tierra en la mezquita. Por último, referente a las puertas, mencionar que el ingreso, al Norte, de la primera mezquita, es de sillería, con la misma disposición que la parte interior de los "mihrab" de las otras mezquitas.

Por último, y para terminar este apartado referente a los aspectos constructivos, queremos recoger una serie de hechos: en primer lugar que, como se observa en el plano, las habitaciones o mezquitas números dos, tres y cuatro poseen un mismo nivel y que para conseguir esto la mezquita número dos se a poya en su frente de poniente en una zapata o cimentación al exterior de considerable grosor que circunda, no sólo el muro de poniente, sino también el muro de mediodía.

En segundo lugar, hay que señalar que esta zapata es utilizada por la mezquita número uno, cuyos muros se apoyan sobre ella, dando la apariencia interior de ser un banco en su muro de levante.

En tercer lugar, hemos podido observar que las mezquitas dos, tres y cuatro poseen un muro de cierre, al Norte, común, al igual que los medianeros, y que sin embargo la fachada a mediodía está realizada por muros adosados a los medianeros, como se comprueba observando los enlucidos; igualmente esta estructura de muros adosados sirve para la realización de los vanos de entrada a las mezquitas.

En cuarto lugar, y basándonos en los datos expuestos anteriormente, hay que decir que la primera mezquita está adosada al muro de la segunda mezquita, lo que nos evidencia su construcción posterior a las restantes. En quinto lugar tenemos que mencionar que en el muro de mediodía de la tercera mezquita, y a la derecha del "mihrab", encontramos una pequeña puerta de 0,47 metros por 0,94 metros, arquitrabada con un sillar que le sirve de sustentante $y$ un suelo enlosado de piedras. Por último, mencionar que todo el edificio se apoya directamente sobre la duna de arena, no presentando cimientos ni suelos, sino simplemente una ligera capa de tierra apisonada que hace las veces de pavimento.

\section{Materiales}

De todo el material aparecido, lo más relevante, en cuanto a número e importancia, son sin lugar a dudas los candiles. Éstos forman un conjunto de una cincuentena, en estado íntegro, más los troceados o fragmentados. Este material es el que predomina en el interior de las habitaciones del complejo religioso, no habiéndose encontrado en este lugar otro tipo de material, si exceptuamos una orza que parece tener la función de almacenar aceite, quizás para alimentar los candiles. Este amplio registro de candiles nos está permitiendo reconstruir la topografía de los candiles en las habitaciones y por tanto conocer la distribución de la iluminación en cada uno de los habitáculos.

Por otro lado, tenemos que mencionar el hecho relevante de que muchos de estos candiles aparecieron en sus correspondientes repisas perforadas en los muros, lo que nos ayuda a comprender la función y servicio que hacían estos objetos en el interior de los edificios religiosos. 
Los candiles, en su totalidad, corresponden al tipo IV de Rosselló Bordoy (1978), es decir, son de amplio recipiente, con carena baja, larga piquera, cuello y asa. Aparecen normalmente decorados con líneas pintadas en rojo en la parte superior del recipiente; a esto, hay que añadir la existencia de otros candiles con restos de vidriado, y uno totalmente vidriado en verde nacarado. Junto a estos candiles, señalar la aparición de un ejemplar con dos mecheros.

Con todo este material, casi monográfico, han aparecido en cantidades menos relevantes, gran número de fragmentos de cerámica hecha a mano con incisiones y peinados, asi como cerámicas hechas a torno con decoración pintada en rojo, que corresponden en su mayoría a jarritas.

Junto a los materiales cerámicos, han aparecido otros documentos de primer orden, como son una serie de paneles de inscripciones grabadas, de tipo epigráfico en cursivo, que en la actualidad están en fase de estudio, así como de su consolidación y protección. Estos paneles se encuentran sobre todo a los dos lados del "mihrab" de la mezquita número uno, y alguna otra inscripción aislada, a la derecha del "mihrab" de la segunda mezquita.

Por último, señalar que gracias a la excavación hemos podido determinar que la lápida encontrada a fines del siglo pasado estaba emplazada en la parte exterior del "mihrab" de la tercera mezquita, pues al comenzar la excavación, y bajados treinta centímetros de la superficie, encontramos que en la parte alta de este "minrab" faltaban tres sillares, de los cuales nos encontramos a esta altura y junto al cubo dos: uno lateral y otro superior que enmarcaba una pequeña losa central. Medidas las dimensiones de esta losa central, vimos que coincidian exactamente con las proporciones de la lápida depositada en el Museo de Murcia. Igualmente, hay que añadir que la piedra utilizada para esculpir la inscripción es idéntica a la utilizada como sillares en este "mihrab». A la vista de estos datos, es fácil suponer que la lápida se encontraba muy cerca de la superficie, a una distancia que, realizado un pequeño sondeo, permitía el verla, por lo que se quitaron los sillares laterales y se extrajo la lápida, quedando en el lugar dichos sillares, como nos los encontramos al comenzar la excavación.

\section{Estratigrafía}

A la vista de lo que llevamos excavado, sólo hemos podido identificar un nivel seguro, que corresponde al nivel de base que enlaza todas las estructuras definidas anteriormente. Junto a este nivel, parece que en determinadas zonas se detecta otro nivel, compuesto por tierra cenicienta, que podría corresponder a un segundo momento de habitación del poblado, pues aparece bastante por encima del nivel inferior. Sin embargo, todavía es muy pronto para definir con exactitud la estratigrafía, pues tenemos que contar con la complejidad que presenta el estar excavando en arena de playa, que no permite con exactitud definir cambios o niveles en los rellenos.

\section{Cronologia}

Gracias a la lápida, que nos da una fecha de finalización de la mezquita en el año $944 \mathrm{~d}$. C., podemos considerar como fecha inicial del conjunto la mencionada, aunque hay que suponer, por lógica, que la instalación de población en el lugar sea algo anterior. Ahora bien, el problema se nos plantea al intentar la fecha del despoblamiento del lugar, que según todos los datos arqueológi- 
cos, nos hacen presuponer que se debió de realizar de forma repentina, pues los materiales aparecieron "in situ", como es el caso del candil que encontramos en su hornacina.

La unidad formal de los candiles nos refuerza esta hipótesis del abandono rápido, pues todos ellos son del mismo tipo, con ligeras variaciones de tamaño. y según la cronología de G. Rosselló, nos llevarían a la primera mitad del siglo XI.

En cuanto a las causas del abandono, pensamos en un principio que podrían deberse a los efectos de la "fitna", pero esta idea la desechamos al percatarnos de que no existían indicios arqueológicos de incendio ni de destrucción violenta producida por hechos bélicos, etcétera, sino más bien da la sensación de una huida o abandono rápido del lugar de la población. A esto habría que añadir que debido a una serie de indicios podemos suponer que se debió a un terremoto. Asi, tenemos que el "mihrab» de la segunda mezquita está volcado en el suelo y esto no creemos que sea fruto de la mano del hombre, pues las dimensiones de la planta y de la zapata harían imposible su vuelco. Igualmente el "mihrab" de la tercera mezquita posee un desplazamiento sobre la vertical de unos treinta centímetros, etcétera. Según estos datos, creemos que el despoblamiento repentino se debió a un terremoto, fenómeno nada extraño en la zona, si pensamos que la actual población de Guardamar es un emplazamiento de nueva planta a consecuencia del terremoto acaecido en $1829^{-}$que destruyó la antigua población ubicada en el castillo. Sobre esta hipótesis del terremoto, tenemos la suerte de comprobar cómo Al-'Udrī (Molina, 1972 ) nos menciona que en el 1048 se produjo un terrible terremoto en la zona inferior del Segura que duró, según él, todo un año, y que llegó a destruir el alminar de la mezquita mayor de Orihuela.

Esta fecha dada por las fuentes coincide con la proporcionada por el material cerámico, por lo que debemos concluir que el poblado se deshabitó hacia la segunda mitad del siglo $X \mid d$. C., aunque tenemos pruebas evidentes de que $\mathrm{e}$ material de sillares y otros elementos se aprovecharon posteriormente en la construcción y amurallamiento del nuevo emplazamiento en el castillo de Guardamar.

\section{Conclusión}

Es demasiado pronto para emitir un juicio sobre la función de las estructuras aparecidas; sin embargo, queremos lanzar una serie de sugerencias, a título de hipótesis, que se irán constatando o refutando al ritmo en que evolucionen las excavaciones.

En principio, creemos que basándonos en la lápida y en los «mihrab», no podemos negar que estas cuatro salas son mezquitas. En segundo lugar, se plantea el problema de identificar la suprafunción que engloba a estos edificios, que desbordan el marco de una simple mezquita rural o de una población pequeña, pues ninguna posee mimbar, luego no debemos pensar que nos encontramos con la mezquita mayor de la comunidad, sino con unas mezquitas utilizadas para otras funciones, de estudio coránico, ¿por el número de candiles?. o de carácter cenobítico, por su pequeño tamaño, que conlleva al recogimiento y aislamiento. En principio nos decantamos por la posibilidad de que estas cuatro mezquitas pertenezcan a una superestructura religiosa, de tipo cenobítico. como pueden ser los denominados «Al-Monastir» o más conocidos como "Rábitas". 
Esta posibilidad, que estamos barajando para explicar la función de estos edificios, es una hipótesis que contemplamos y en la que estamos investigando en la actualidad, aunque plantea problemas, como por ejemplo que las fuentes no lo recojan; éste es el caso de Al-'Udrī, que en su minucioso "Tarsì al-ajbār» no menciona la existencia de una rábita en la desembocadura del Segura, a la cual denomina como un lugar de meandros: "Almudawar»; quizás esto se deba a que cuando escribió su obra ya no existía el lugar por los efectos del terremoto, pero creemos que existiría su recuerdo.

Por otro lado, nos extraña que no hava quedado ningún registro toponímico del lugar, ya sea como "Al-Monastir» y sus derivaciones o Rábita, como hay en otros lugares de Al-Andalus.

Por estas razones, nos reservamos el poder lanzar una definición más exacta, mientras no poseamos más datos de los actuales.

Abril de 1985

\section{Bibliografía}

AL-IDRISI, «Nuzhat a/-mušsāqu», apud Geografia de España, Valencia, 1974, traducción castellana de Saavedra y Blázquez de la traducción francesa de R. Dozy y Goeje (ed. facsimill, p. 187.

AL-'UORİ, aTarși al-ajbårn, apud MOLINA LÓPEZ, E., 1972, "La Cora de Tudmir según Al-'Udri (s, XI). Aportaciones al estudio geográfico-descriptivo del SE peninsular», Cuadernos de Historia del lslam, 4, serie monográfica n. ${ }^{\circ} 3$, página 45

AZUAR RUIZ, R., 1981, Castellología Medieval Alicamina. Area meridional, Alicante, pp. 115-124.

CODERA, F., 1897, "Inscripción árabe de Guardamar", Boletin de la Real Academia de la Historia, XXXI, pp. $31-33$.

EPALZA, Míkel de, 1980, "Al topónimo de Guardamar", Revista del instituto de Estudios Alicantinos, 29, págjnas 205-214.

ROSSELLO BORDOY, G., 1978, Ensayo de sistematización de la cerámica arabe de Mallorca, Palma de Mallorca.

VALLVÉ BERMEJO, J., 1976, “Notas de metrología hispano-árabe. El codo en la España musulmana», Al-Andalus, $\mathrm{XLI}, 2, \mathrm{pp}, 339-354$ 

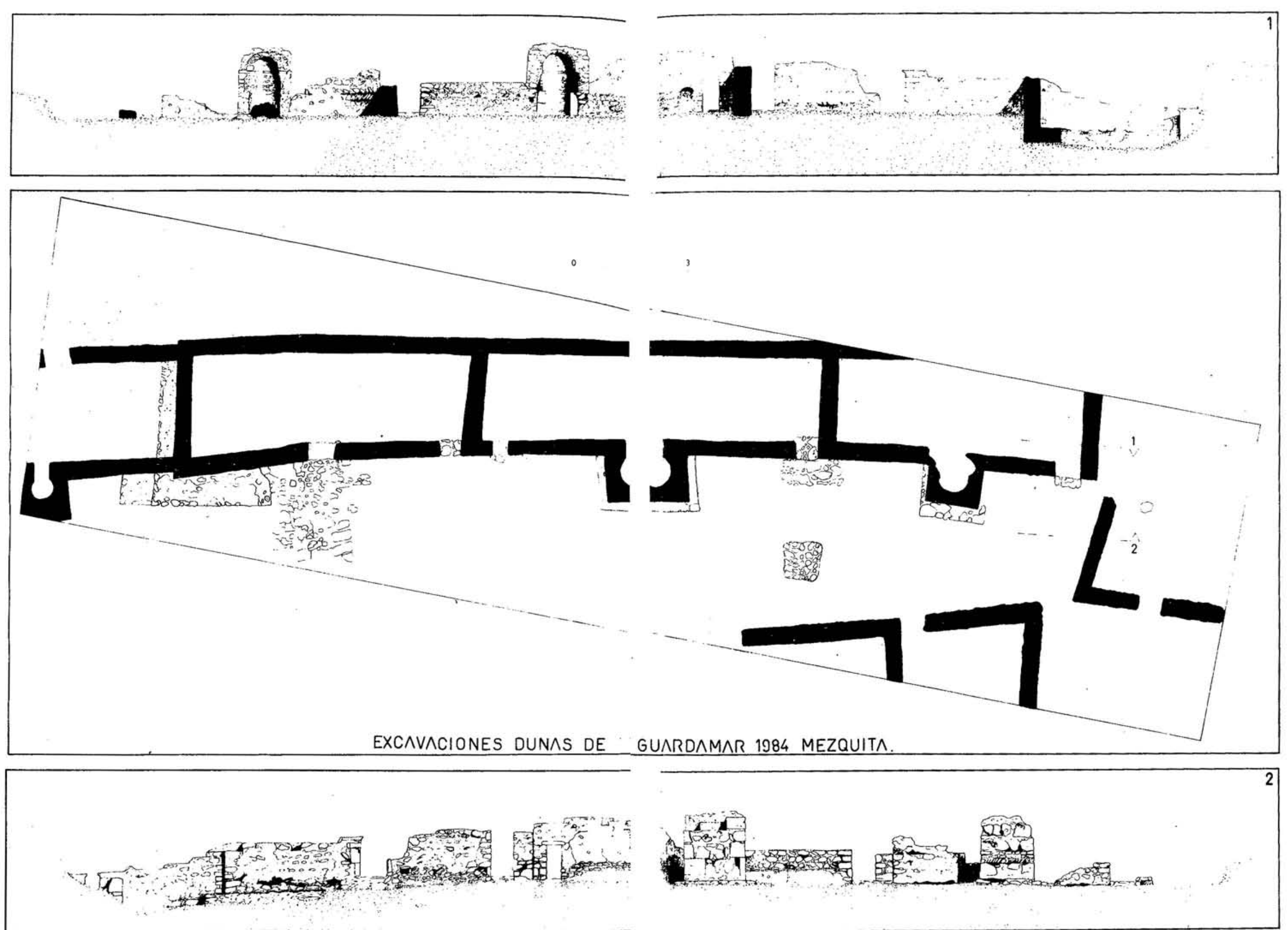


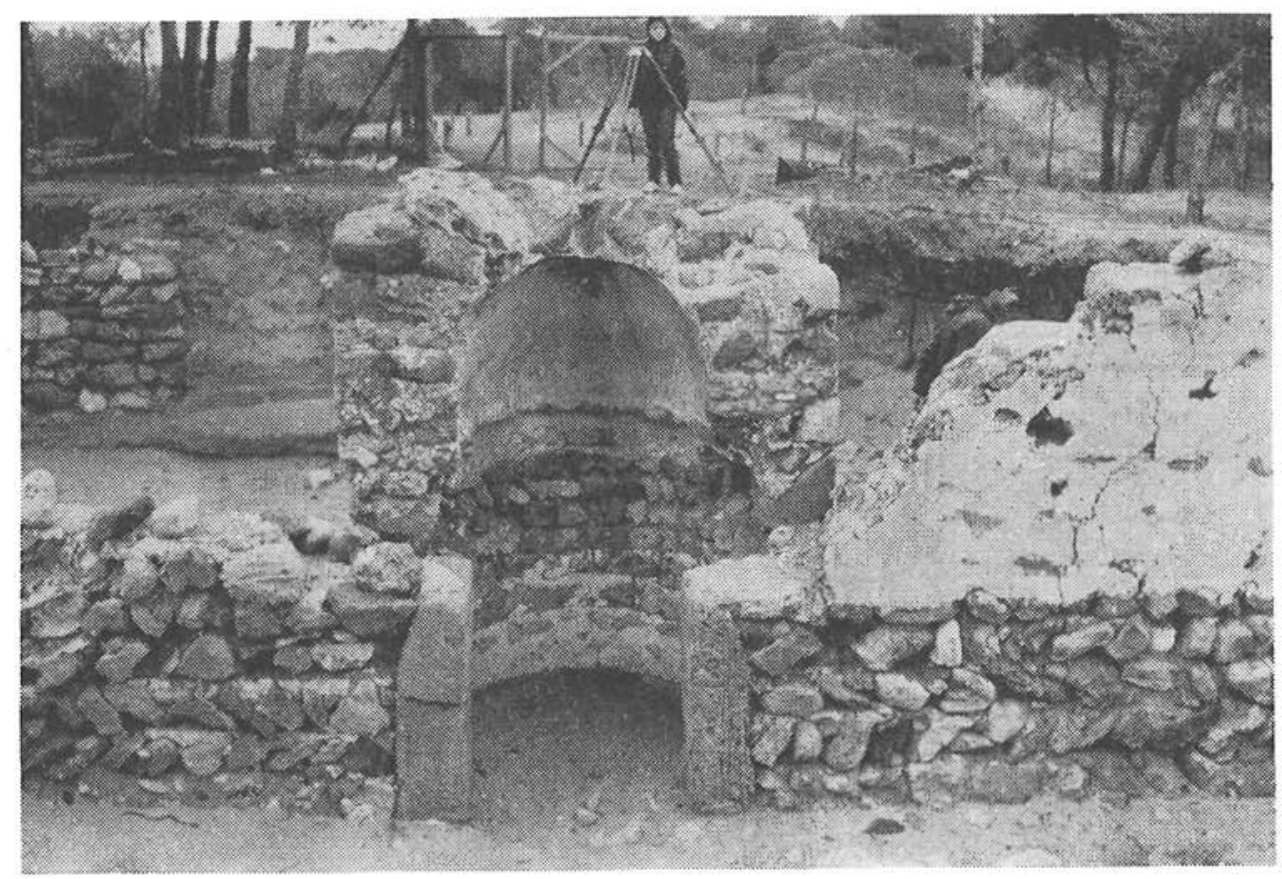

Foto núm. 1.-Vista parcial del conjunto, en la que se aprecia la parte exterior de dos mihrab.

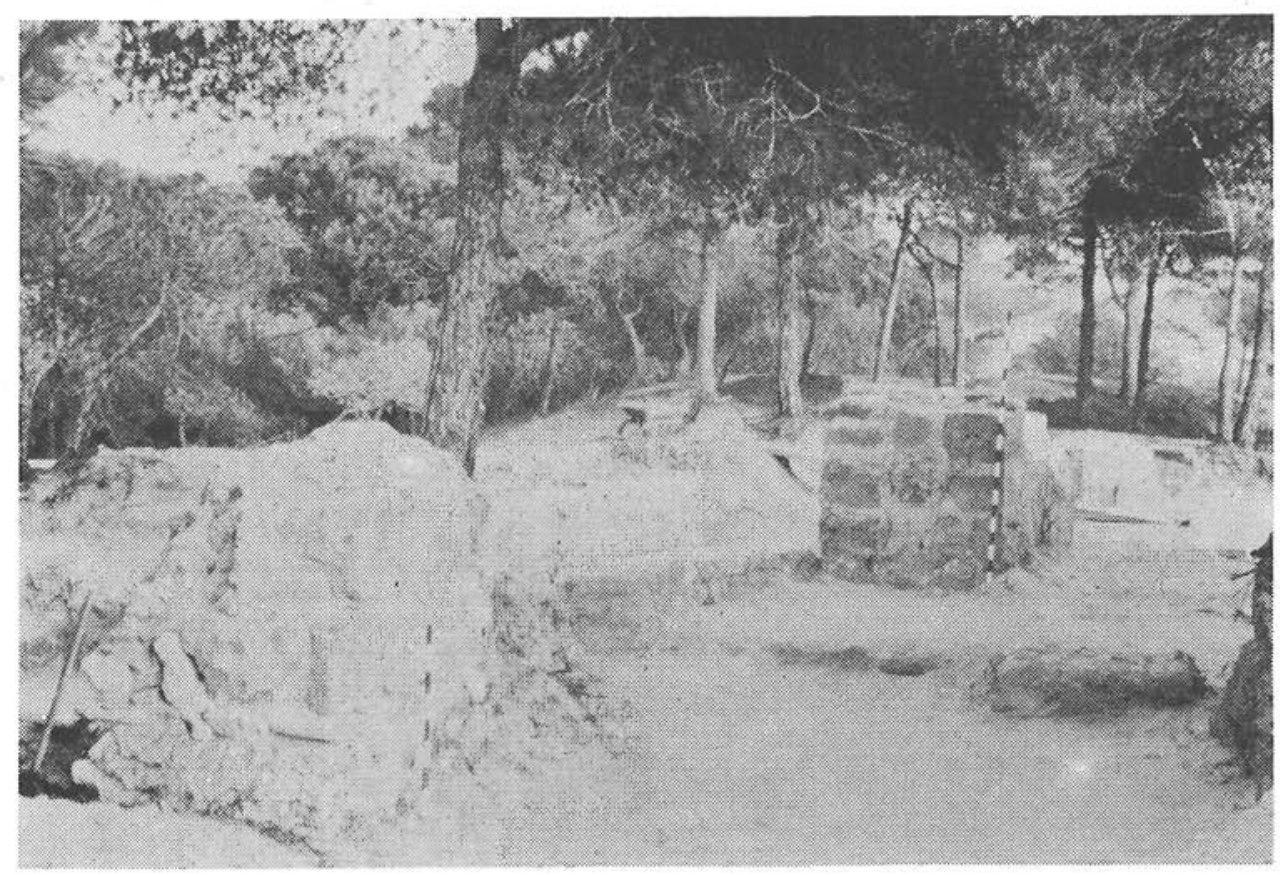

Foto núm. 2.-Vista interior del Mihrab principal. 


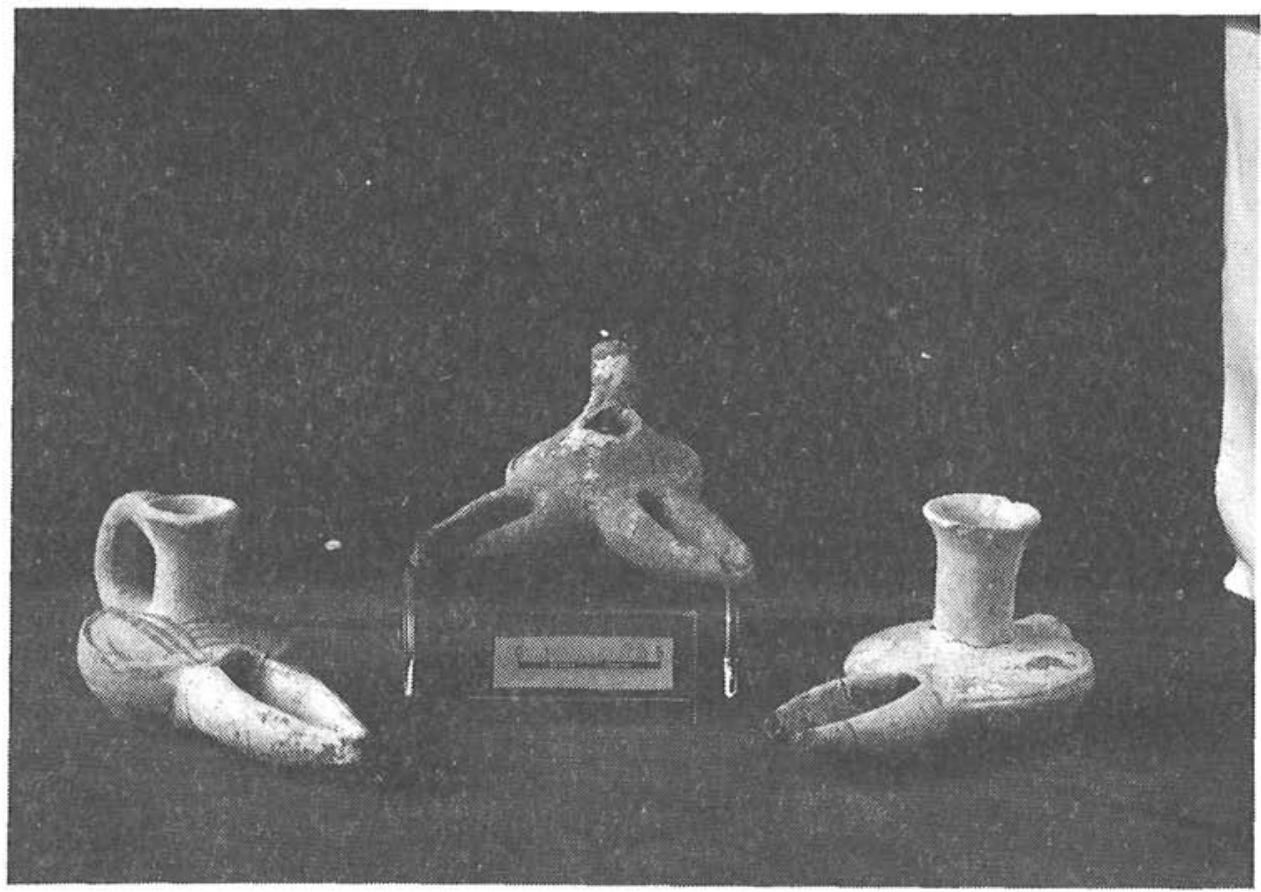

Foto núm. 3.-Candiles aparecidos en la excavación.

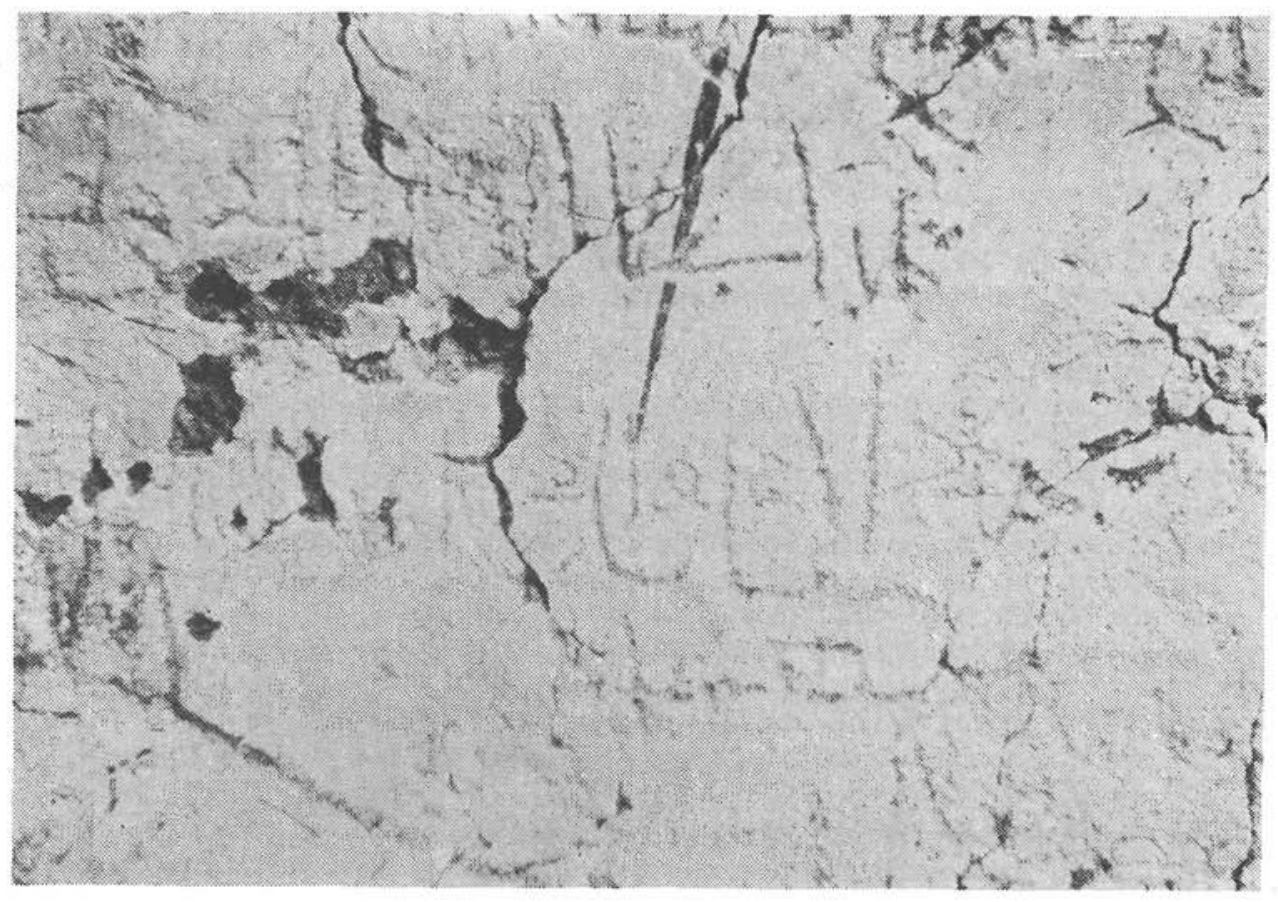

Foto núm. 4.-Detalle de las inscripciones aparecidas. 


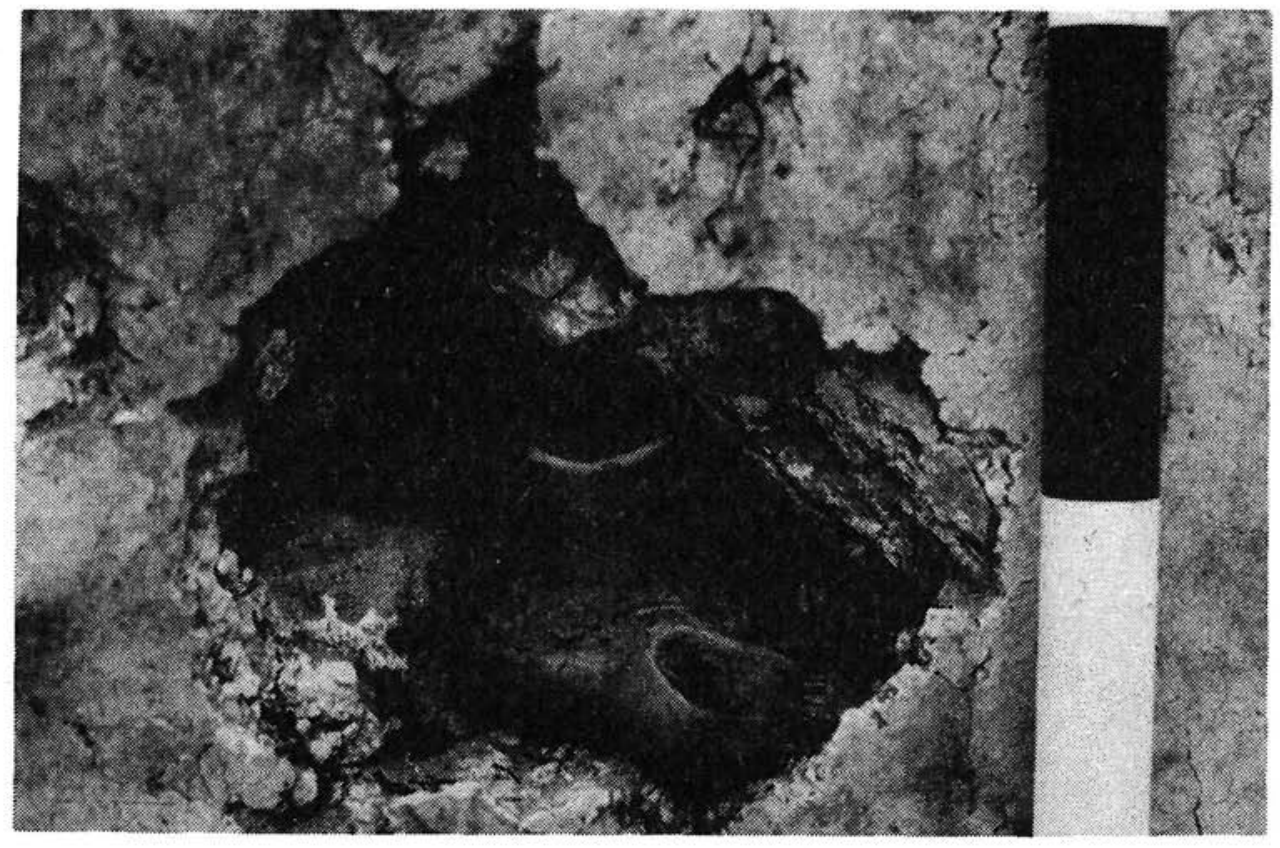

